\title{
O GRUPO ARARAS (NEOPROTEROZÓICO) NA PARTE NORTE DA FAIXA PARAGUAI E SUL DO CRATON AMAZÔNICO, BRASIL
}

\author{
AFONSO CÉSAR RODRIGUES NOGUEIRA ${ }^{1,2} \&$ CLAUDIO RICCOMINI ${ }^{2,3}$
}

\begin{abstract}
Resumo O Grupo Araras, de idade neoproterozóica, é redescrito e redefinido com base em dados faciológicos e estratigráficos oriundos da parte norte da Faixa Paraguai, região sul do Cráton Amazônico, Estado do Mato Grosso, Brasil. Esta unidade, composta predominantemente de rochas carbonáticas, de aproximadamente $600 \mathrm{~m}$ de espessura, sobrepõe-se a diamictitos glaciais da Formação Puga e é recoberta pelas rochas siliciclásticas do Grupo Alto Paraguai. A sucessão do Grupo Araras foi subdividida em quatro formações: 1) Mirassol d'Oeste, constituída por dolomitos finos peloidais e dolomitos com estromatólitos; 2) Guia, que consiste em calcários finos betuminosos, folhelhos e brechas calcáreas, localmente dolomitizados; 3) Serra do Quilombo, constituída por dolomitos finos, dolomitos arenosos, brechas com cimento de dolomita e brechas com matriz; e 4) Nobres, encerrando dolomitos finos, arenitos, brechas e conglomerados dolomíticos, pelitos e níveis de sílex secundário. O Grupo Araras foi depositado em plataforma profunda (formações Mirassol d'Oeste, Guia e Serra do Quilombo inferior) e rasa com influência de processos de tempestades e maré (formações Serra do Quilombo superior e Nobres). A Formação Mirassol d'Oeste e a base da Formação Guia, na região ao sul do Cráton Amazônico, constituem a capa carbonática depositada após o evento glacial Puga, correlato ao episódio Marinoan (final há $\sim 630 \mathrm{Ma}$ ) inserido no contexto de glaciações de baixa-latitude de acordo com a hipótese de snowball Earth. O estudo estratigráfico detalhado do Grupo Araras estabeleceu a base para a correlação global desses depósitos com outras unidades neoproterozóicas pós-glaciais do mundo.
\end{abstract}

Palavras-chaves: Grupo Araras, rochas carbonáticas, litoestratigrafia, Neoproterozóico, Faixa Paraguai, Cráton Amazônico.

\begin{abstract}
THE NEOPROTEROZOIC ARARAS GROUP IN THE NORTHERN PARAGUAY BELT AND SOUTH AMAZON CRATON, BRAZIL The Neoproterozoic Araras Group is redescribed and redefined on the basis of facies and stratigraphic data from the northern Paraguay belt and south of the Amazon craton, State of Mato Grosso, Brazil. This predominantly carbonatic unit reaches approximately $600 \mathrm{~m}$ thick, overlies glaciogenic diamictites of the Puga Formation and is covered by siliciclastic rocks of the Alto Paraguai Group. The Araras Group succession was divided into four formations: (1) Mirassol d'Oeste, composed of fine-grained dolostone and dolostone with stromatolite; (2) Guia, with fine-grained bituminous limestone, shale and calcareous breccia, locally dolomitized; (3) Serra do Quilombo, consisting of fine-grained dolostone, sandy dolostone and sparry dolomite cemented-breccia and matrix-supported breccia; and (4) Nobres, comprising fine-grained dolostone, dolomitic breccia and conglomerate, sandstone, pelite and layers of secondary chert. The Araras Group was deposited in a platform of deep to moderately deep waters (Mirassol d'Oeste, Guia and Lower Serra do Quilombo formations) and under storm and tidal influences (Upper Serra do Quilombo and Nobres). The Mirassol d'Oeste Formation and the base of Guia Formation, in the southwest of Amazon craton, constitute a Neoproterozoic cap carbonate deposited after the Puga glacial event correlated to the Marinoan episode, within the context of the lowlatitude glaciations according with the snowball Earth hypothesis. The detailed stratigraphic study of Araras Group has established the basis for global correlation of these deposits with other Neoproterozoic post-glacial units around the world.
\end{abstract}

Keywords: Araras Group, carbonate rocks, lithostratigraphy, Neoproterozoic, Paraguay belt, Amazon craton.

INTRODUÇÃO Rochas carbonáticas de idade neoproterozóica distribuídas ao longo da margem sul do Craton Amazônico e segmento norte da Faixa Paraguai são relacionadas ao Grupo Araras, definido no trabalho clássico de Almeida (1964). O interesse crescente pelos depósitos carbonáticos neoproterozóicos nos últimos anos tem colocado a Faixa Paraguai em destaque na literatura mundial, uma vez que suas rochas também registram anomalias climáticas, geoquímicas e bioevolutivas que podem fornecer indicações importantes para o surgimento da vida (Nogueira et al. 2003). Embora definidas inicialmente como um grupo, estas rochas carbonáticas não foram imediatamente subdivididas formalmente em formações. As propostas estratigráficas posteriores, baseadas parcial ou totalmente na classificação de Almeida (1964), apesar de ampla divulgação na literatura, ainda não possuem critérios para uma formalização adequada e consensual dos termos litoestratigráficos. Os arcabouços estratigráficos são preliminares e geralmente calcados em descrições pouco precisas e de cunho essencialmente litológico. O presente estudo estratigráfico do Grupo Araras em afloramentos nas regiões de Mirassol d'Oeste, Tangará da Serra, Cáceres, Guia, No- bres e Bauxi, Estado do Mato Grosso, bem como a integração dos principais trabalhos sobre o grupo, permitiram sua redescrição e redefinição litoestratigráfica de acordo com a proposição de Petri et al. (1986), auxiliada pela análise de fácies (Walker 1992) (Fig. 1). Este procedimento levou a caracterizar os litotipos do Grupo Araras, subdividindo-o em formações, além de melhorar o entendimento dos processos deposicionais e interpretações paleoambientais, bem como correlacionar estes depósitos com os eventos anômalos ocorridos no Neoproterozóico.

PROCEDIMENTOS DE CAMPO Os depósitos do Grupo Araras, com espessuras de centenas de metros, formam serras com até $600 \mathrm{~m}$ de altitude, as quais são geralmente recobertas por solos e vegetação, condições que contribuem para a escassez de afloramentos, dificultando assim a investigação estratigráfica contínua. Por outro lado, pedreiras e cortes de estrada mostraram-se adequados para a análise estratigráfica e sedimentológica. Exposições isoladas e com reduzida espessura, mesmo intemperizadas, serviram para o controle da distribuição das fácies. Áreas com proeminente deformação tectônica, próximas

11 Departamento de Geologia, Centro de Geociências, Universidade Federal do Pará, CP 1611, 66.075-900, Belém, PA, Brazil, anogueira@ufpa.br.

2 Bolsista de produtividade em pesquisa do CNPq.

3 Departamento de Geologia Sedimentar e Ambiental, Instituto de Geociências, Universidade de São Paulo, Rua do Lago, 562, 05508-080, São Paulo, SP, Brazil, riccomin@usp.br. 
a zonas de falhas, foram evitadas e as seções medidas foram levantadas em flancos de dobras, sem duplicar estratos, permitindo reconstituir em diversos locais o empilhamento sedimentar primário.

Para a descrição e denominação dos litotipos carbonáticos foram utilizadas as classificações de Folk (1974) e de Durham (1962). O termo fácies é aqui empregado no mesmo sentido de "litofácies carbonática” (Kerans \& Tinker 1997), formada por elementos descritivos básicos tridimensionais definidos pelas estruturas sedimentares, grãos componentes, fábricas e, quando presentes, pelo tipo e morfologia de estromatólitos.

\section{CONTEXTO GEOLÓGICO O Grupo Araras está expos-} to em estrutura homoclinal na margem sul-sudoeste do Cráton Amazônico e principalmente na zona de cavalgamento e dobramento da parte norte da Faixa Paraguai, no contexto da parte sul da Província Tapajós e oeste e noroeste da Província Tocantins (Almeida 1984) (Fig. 1). A Faixa Paraguai foi denominada de Geossinclíneo Paraguai por Almeida $(1964,1965,1974,1984)$ que a subdividiu em faixas tectônicas de SE para NW, de acordo com o grau de metamorfismo e deformação. Essa mesma definição foi adotada em outras propostas, alterando apenas a nomenclatura (e.g. Alvarenga 1988 e 1990). A Faixa Paraguai representa um extenso orógeno neoproterozóico resultante da convergência e colisão de três blocos continentais: a oeste a

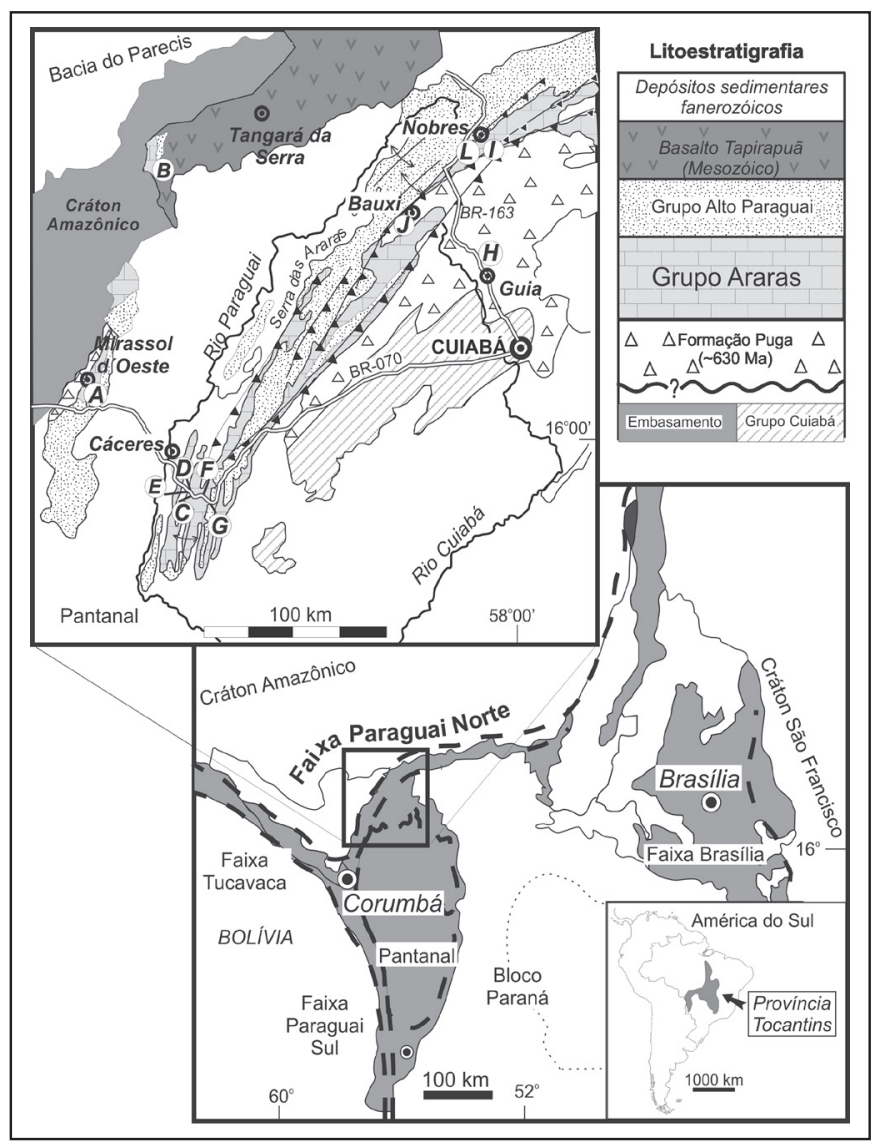

Figura 1. Litoestratigrafia e contexto tectônico do sul do Cráton Amazônico com a localização dos principais perfis estudados (círculos com letras no mapa destacado). Localidades: (A) Pedreira Terconi, Mirassol d'Oeste, (B) Pedreira Calcário Tangará, (C) Fazenda Jacobina, (D e E) Pedreira Camil-Emal 1 e 2 no km 707 da BR-070, (F) km 698 da BR-070, (G) km 690 da BR-070, (H) Pedreira Nossa Senhora da Guia, (I) Copacel, Nobres, (J) Mineração Itaipu-Bauxi, (L) $1 \mathrm{~km}$ a $S W$ de Nobres.
Amazônia, a leste São Francisco-Congo e ao sul Paraná ou Rio de la Plata, este último coberto por rochas fanerozóicas da Bacia do Paraná (Almeida 1984) (Fig. 1). Este evento de convergência tem sido atribuído às orogêneses Brasiliana/Pan-Africana (600520 Ma; Almeida 1984, Trompette 1994) e Paraguai (540-490 Ma; Basei \& Brito Neves 1992). Eventos distensivos posteriores resultaram em intrusões graníticas de idade em torno de 500 Ma, fornecida pela datação do Granito São Vicente (Almeida \& Mantovani 1975).

NOMENCLATURA ESTRATIGRÁFICA E PALEOAMBIENTE $O$ estudo e a história da nomenclatura estratigráfica dos carbonatos neoproterozóicos da Faixa Paraguai remontam ao século 19, quando o Estado do Mato Grosso, antes de ser dividido, era estudado em dois alvos principais: a Província Serrana, ao norte e objeto deste trabalho, e a região de Corumbá e Serra do Bodoquena, ao sul (Fig. 1). As primeiras menções às rochas carbonáticas aflorantes no segmento norte da Faixa Paraguai foram feitas por Castelnau (1850) na região de Nobres e Cáceres. Evans (1894) descreveu as rochas carbonáticas da Província Serrana denominando-as de "Arara Limestone" em alusão ao vilarejo Araras, atualmente com o nome de Bauxi, com seção-tipo entre a cabeceira do rio Paraguai e sua confluência com o rio Cuiabá. Correlações litoestratigráficas com as rochas carbonáticas do Grupo Corumbá, aflorantes no segmento sul da Faixa Paraguai (Fig. 1), são freqüentes na literatura (Evans 1894, Lisboa 1909, Oliveira \& Moura 1944, Oliveira 1964, Correa \& Couto 1972, Olivatti 1976, Almeida 1984, Alvarenga \& Trompette 1994). As rochas carbonáticas Araras foram categorizadas como "série" (Oliveira \& Moura 1944, Oliveira \& Leonardos 1943, Scorza 1960, Oliveira 1964) e principalmente como "formação", inserida tanto no Grupo Corumbá quanto no Grupo Alto Paraguai (Fig. 2).

Almeida (1964) propôs a categoria de "grupo" para estes carbonatos com duas possíveis formações, uma inferior pelítica-carbonática e uma superior de composição dolomítica (Fig. 2). Este autor manteve sua definição informal em vários trabalhos subseqüentes (Almeida 1965, 1967, 1968, 1974, 1984). A definição de "grupo" de Almeida (1964) foi usada por Hennies (1966), que sugeriu para as formações inferior e superior os nomes Guia e Nobres, respectivamente (Fig. 2). Após a proposição destas unidades, o Grupo Araras tem sido descrito como uma sucessão de calcários sobrepostos por dolomitos e, muitas vezes, inseridos inadequadamente em unidades informais ou "fácies" e "seqüência" como sinônimos de unidade litoestratigráfica (Fig. 2).

Nas primeiras interpretações paleoambientais das rochas carbonáticas do SW do Cráton Amazônico foram inferidos prin-

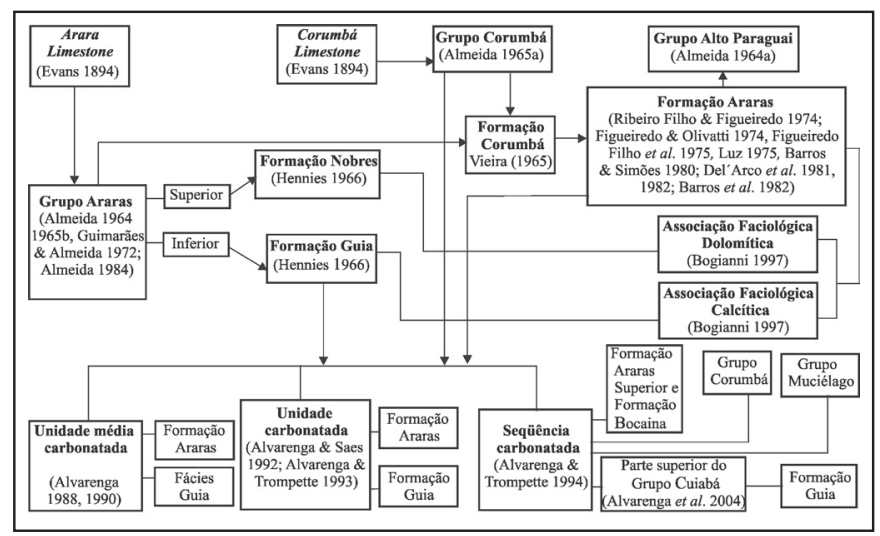

Figura 2. Nomenclatura estratigráfica do Grupo Araras. 
cipalmente depósitos de plataforma marinha (Almeida 1964, Luz et al. 1978, Barros et al. 1982). Estudos sedimentológicos posteriores, baseados na análise de afloramentos isolados, interpretam depósitos de planície de maré sob condições evaporíticas e depósitos de águas profundas (Zaine 1991, Boggiani 1997).

IDADE E CORRELAÇÃo Não existem idades radiométricas para as rochas carbonáticas do Grupo Araras. Até o momento não foram encontrados tufos ou corpos vulcânicos que sirvam para essa finalidade. Tentativas de datação foram feitas para argilitos das formações Sepotuba $(\mathrm{Rb} / \mathrm{Sr}-569 \pm 20 \mathrm{Ma}$; Cordani et al. 1978, Bonhomme et al. 1982) e Diamantino (Rb/Sr - 660 60 Ma; Cordani et al. 1985) do Grupo Alto Paraguai, sobrepostos ao Grupo Araras. Estas idades foram inicialmente interpretadas como deposicionais, depois como marcadoras do evento Brasiliano, e atualmente de significado incerto. A datação do Granito São Vicente (K/Ar e Rb/Sr - 500 Ma; Hasui \& Almeida 1970, Almeida \& Mantovani 1975), intrusivo no Grupo Cuiabá, fornece a idade mínima para toda sucessão sedimentar da Faixa Paraguai (Fig. 1).

As indicações relativas de idade para o Grupo Araras se baseiam na correlação com as rochas carbonáticas do Grupo Corumbá, da região topônima, $500 \mathrm{~km}$ a SW da Província Serrana (Fig.1). Embora os dois grupos apresentem microfósseis semelhantes, considerados neoproterozóicos, tais como Bavlinella faveolata, Siphonophycus sp., Symplassophaeridium sp., Leiosphaeridia sp., Soldadophycus bossii e filamentos cianobacterianos, estes não são indicadores de idade (Hidalgo 2002, Gaucher et al. 2003). Por outro lado, o topo do Grupo Corumbá contém macrofósseis como Vendotaenia, Corumbella werneri e Cloudina (Hahn et al. 1982, Walde et al. 1982, Zaine 1991) interpretados como penecontemporâneos à biota Ediacara.

Os grupos Araras e Corumbá recobrem diamictitos da Formação Puga, considerados como produto da glaciação Marinoan, encerrada há cerca de $630 \mathrm{Ma}$. Capas carbonáticas ocorrem na base destes grupos e exibem valores de $\delta^{13} \mathrm{C}$ próximos de -5 $\%$ PDB, típicos de eventos glaciais do final do Neoproterozóico, e razões de ${ }^{87} /{ }^{86} \mathrm{Sr}$ próximas a 0,7081 , que caracterizam capas carbonáticas depositadas após a glaciação Marinoan (Boggiani 1997, Nogueira et al. 2003, Alvarenga et al. 2004). Estes carbonatos são encontrados em sucessões neoproterozóicas de várias partes do mundo, formadas por eventos de deposição anômala ocorridos após a glaciação global (Kennedy et al. 2001, Hoffman \& Schrag 2002, Haverlson et al. 2004). A presença deste marco estratigráfico pode indicar que pelo menos a sucessão basal de ambos os grupos pode ser correlacionadas com outras sucessões neoproterozóicas, além de indicar a idade Ediacarana (600-542 Ma). Esta idade é também sugerida pela magnetização primária encontrada nos carbonatos da base do Grupo Araras (600-580 Ma) e pela magnetização secundária adquirida no final da orogenia Brasiliana entre 540 e $520 \mathrm{Ma}$ (Trindade et al. 2003). A máxima ocorrência de Cloudina em sucessões neoproterozóicas, em torno de $\sim 548 \mathrm{Ma}$ (Corsetti \& Hagadorn 2002), pode ser usada aqui para inferir a idade mínima para o final da deposição carbonática na Faixa Paraguai.

\section{LITOESTRATIGRAFIA}

Espessura A sucessão carbonática do Grupo Araras tem espessura estimada de até $600 \mathrm{~m}$ obtida pela soma das espessuras de cada unidade correlacionadas com auxílio das principais superfícies estratigráficas (Fig. 3). A espessura total dos calcários da Formação Guia é consensualmente considerada como sendo de 200 m (Almeida 1964, Hennies 1966, Luz et al. 1978, Alvarenga et al. 2004). A espessura de $\sim 500 \mathrm{~m}$ sugerida por Almeida (1964) para os dolomitos acima dos calcários é admitida neste trabalho, sendo significantemente inferior aos $1.100 \mathrm{~m}$ propos- tos por Luz et al. (1978). Esta espessura superestimada foi provavelmente obtida pela soma das espessuras dos dolomitos que ocorrem na porção superior do Grupo Araras com aqueles da base da Formação Raizama, muitas vezes de difícil distinção somente pelo aspecto litológico (Silva Júnior et al. 2005).

Distribuição das unidades $\mathrm{O}$ mapeamento das unidades sedimentares do Grupo Araras sempre foi realizado levando em consideração os dois litotipos principais, dolomitos e calcários (Fig. 2). Os dolomitos da capa carbonática da região de Mirassol d'Oeste são os litotipos de menor expressão em área do Grupo Araras, sendo restritos à borda sul do Cráton Amazônico e provavelmente adelgaçam em direção à Faixa Paraguai Norte, onde não foram encontrados até o momento (Fig. 3). Os calcários da Formação Guia foram facilmente diferenciados em trabalhos anteriores, enquanto os depósitos dolomíticos foram mapeados como sendo uma única formação, com a designação de "Nobres". Retirando os efeitos do intemperismo e da dolomitização, e seguindo as descrições apresentadas neste trabalho, foi possível separar duas unidades dolomíticas na escala 1:25.000.

A distribuição dos litotipos que caracterizam uma extensa plataforma marinha é refletida diretamente na exposição por quilômetros destes depósitos (Fig. 1, 3). Os litotipos do Grupo Araras são em geral muito homogêneos e, apesar da descontinuidade dos afloramentos, mesmo naqueles com poucos metros de espessura, é possível identificar a provável associação de fácies e a unidade litoestratigráfica, o que contribuiu para a precisa correlação dos depósitos.

A proposta litoestratigráfica para o Grupo Araras utilizada neste trabalho segue, em parte, a sugestão de Almeida (1964) e utiliza a terminologia de Hennies (1966) por ordem de prioridade (Fig. 2). As rochas carbonáticas deste grupo sobrepõemse aos diamictitos glaciais da Formação Puga, estão recobertas pelas rochas siliciclásticas da Formação Raizama (Grupo Alto Paraguai) e podem ser agrupadas em quatro formações: Mirassol d'Oeste, Guia, Serra do Quilombo e Nobres.

\section{Unidades sedimentares}

FORMAÇÃO MIRASSOL D'OESTE O holoestratótipo da Formação Mirassol d'Oeste é a mina Terconi, em Mirassol d'Oeste, que representa a melhor exposição descrita até o momento (Fig. 4). O paraestratótipo desta unidade ocorre nas proximidades da mina Terconi, na Chácara Santo Antonio. Considera-se como hipoestratótipo a sucessão encontrada na mina de calcário Tangará (Figs. 1, 2). A proposição desta unidade estratigráfica é justificada pela sua mapeabilidade e por representar a unidade dolomítica de uma capa carbonática pós-glaciação Marinoan (Nogueira et al. 2001a, 2003, Allen \& Hoffman 2004). Assim, como em outros sítios pré-cambrianos, as capas carbonáticas são formalmente contextualizadas em unidades litoestratigráficas (Kennedy 1996, Hoffman \& Schrag 2002).

A Formação Mirassol d'Oeste exibe espessura de até $15 \mathrm{~m}$, sendo constituída por dolomito fino (dolomudstone) e dolomito com pelóides (dolomudstone com pelóides) de coloração rosa$\mathrm{da}$, dispostos em camadas lateralmente contínuas por dezenas de metros. Na base da unidade o dolomito fino rosado sobrepõe-se diretamente ao diamictito maciço, com clastos centimétricos a decimétricos de arenito e granito disseminados em matriz argilo-arenosa, correspondente à Formação Puga (Fig. 4). O contato entre ambas as unidades é brusco, lateralmente irregular e ondulado, relacionado ao desenvolvimento de estruturas de sobrecarga no dolomito fino (Fig. 5A). No contato, o dolomito sobreposto exibe acamamento maciço, laminação plana, deformada e convoluta, e níveis de brechas e estruturas de injeção subordinados. Localmente, a laminação plana incipiente ocorre no dolomito com estrutura de sobrecarga, às vezes sugerindo 


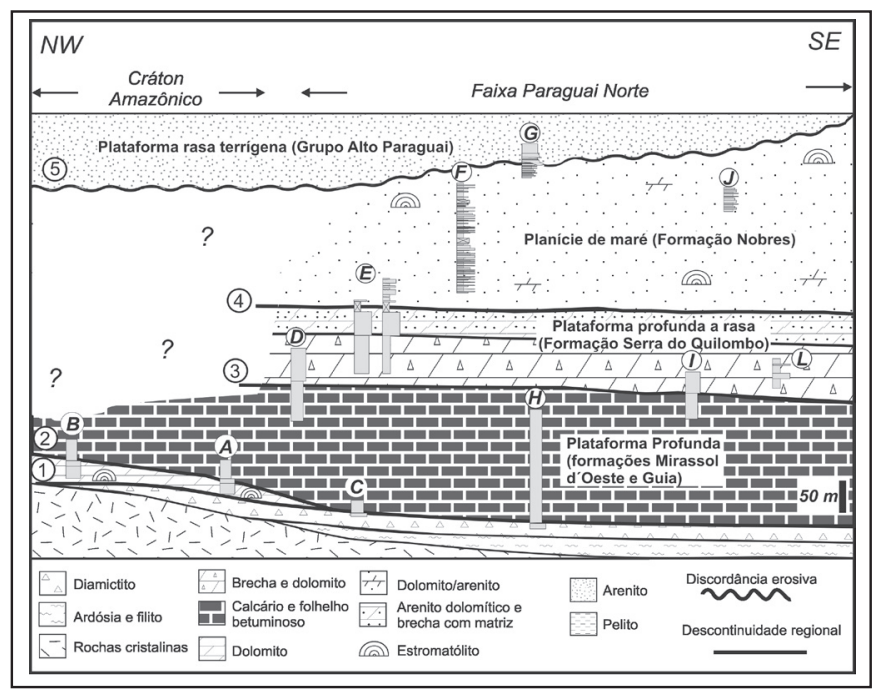

Figura 3. Correlação estratigráfica dos perfis estudados do sul do Cráton Amazônico e Faixa Paraguai Norte. A correlação se baseia nos principais contatos litoestratigráficos (1 a 5) e associações gerais de fácies. Localização dos perfis na Figura 1. A distribuição horizontal dos perfis é esquemática.

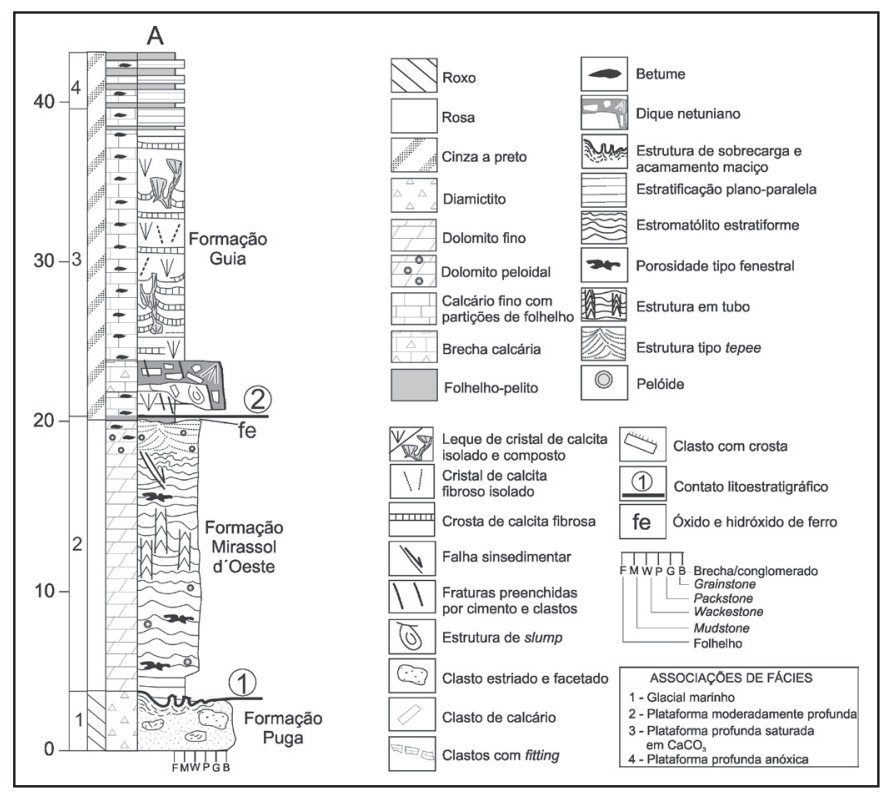

Figura 4. Holoestratótipo da Formação Mirassol d'Oeste e base da Formação Guia aflorantes na Mina Terconi. disposição em onlap. A laminação microbiana forma estromatólitos planares fenestrais (doloboundstone microbiano com pelóides), raramente dômicos, com comprimento da ondulação de até $70 \mathrm{~cm}$ e amplitude de 10 a $20 \mathrm{~cm}$ (Fig. 4 e 5B). Localmente, ocorrem estruturas tipo tubo com comprimento centimétrico e diâmetro de até $3 \mathrm{~cm}$, interrompendo e deslocando a laminação microbiana, sendo preenchida por dolomita espática e/ou dolomito fino.

O topo da Formação Mirassol d'Oeste é caracterizado por dolomito fino com pelóides (dolopackstone com pelóides) com níveis exibindo porosidade interpartícula preenchida por betume, conferindo um aspecto finamente listrado à rocha. Esta laminação é suavemente arqueada, formando cristas com comprimento de onda de $0,15-0,7 \mathrm{~m}$, podendo alcançar até $2 \mathrm{~m}$, e amplitude de 10 a $20 \mathrm{~cm}$, espaçadas lateralmente por 2 a $3 \mathrm{~m}$ (Fig. 5C). Embora lembrem a estrutura tepee, não constituem as clássicas formas poligonais descritas para o Fanerozóico (Shinn 1983, Kendall \& Warren 1987); ao contrário, possuem cristas alongadas, por mais de $3 \mathrm{~m}$, na direção NNW, e internamente exibem estruturas produzidas por onda como laminação truncada de baixo ângulo e com padrão em chevron e pinch and swell, sendo interpretadas como megamarcas onduladas (cf. Allen \& Hoffman 2004). A associação desta estrutura com falhas pode sugerir também uma origem por deformação sinsedimentar. O limite superior da Formação Mirassol d'Oeste é geralmente planar a erosivo, em contato com calcários com leques de cristais, calcarenitos e brechas calcárias (Fig. 5D, 5E).

$\mathrm{O}$ contato basal irregular com o desenvolvimento de estruturas de sobrecarga foi resultante de fluxo plástico e liquefação de sedimentos incoesos a parcialmente consolidados. Por outro lado, a configuração em onlap da laminação pode sugerir que, em parte, uma paleotopografia foi acentuada posteriormente pelo processo de deformação sinsedimentar. Esta hipótese sugere uma precipitação mais lenta para estes carbonatos, também indicada por múltiplas reversões paleomagnéticas encontradas nesta sucessão (Trindade et al. 2003). O contato brusco da capa carbonática com o diamictito glacial indica mudança das condições glaciais (icehouse) para as de efeito estufa (greenhouse), de acordo com a hipótese de snowball Earth (cf. Hoffman et al.1998).

A tipologia dos estromatólitos (micríticos, em parte com pelóides, e na forma de biostroma) acusa atividade microbiana no assoalho marinho plano, em ambiente de baixa energia sem a atuação significativa de correntes. A falta de indicadores típicos de perimaré (gretas de ressecação, moldes de evaporitos etc) associados aos estromatólitos sugere contexto de plataforma marinha, abaixo da base de ondas de tempestade, porém ainda dentro da zona eufótica. Fluxo oscilatório e/ou combinado (tempestades?) induziram a migração de megamarcas onduladas em ambiente moderadamente profundo. O mecanismo de formação da estrutura em tubo ainda é pouco explicado, tendo sido relacionados ao escape de hidratos de gás (Kennedy et al. 2001) ou produto da atividade microbiana (Hoffman \& Schrag 2002).

FORMAÇÃO GUIA A seção mais completa e holoestratótipo da Formação Guia ocorre na Mina Nossa Senhora da Guia, onde alcança espessura acima de $150 \mathrm{~m}$, exposta em um sinclinal com vergência para NW e eixo orientado segundo NE-SW (Fig. 6). É descartada aqui qualquer relação deste holoestratótipo com a parte superior do Grupo Cuiabá (Fig. 2). O Sinclinal de Guia é considerado um testemunho do Grupo Araras preservado dos processos de dissecação do relevo ocorridos no Fanerozóico.

A camada mais basal da Formação Guia é formada por pelitos vermelhos com até $10 \mathrm{~cm}$ de espessura recobertos por calcários finos (mudstones calcíferos), cinzentos a pretos e betuminosos, que formam camadas de 10 a $20 \mathrm{~cm}$ de espessura, com partições de lâminas de folhelho, formando uma sucessão 


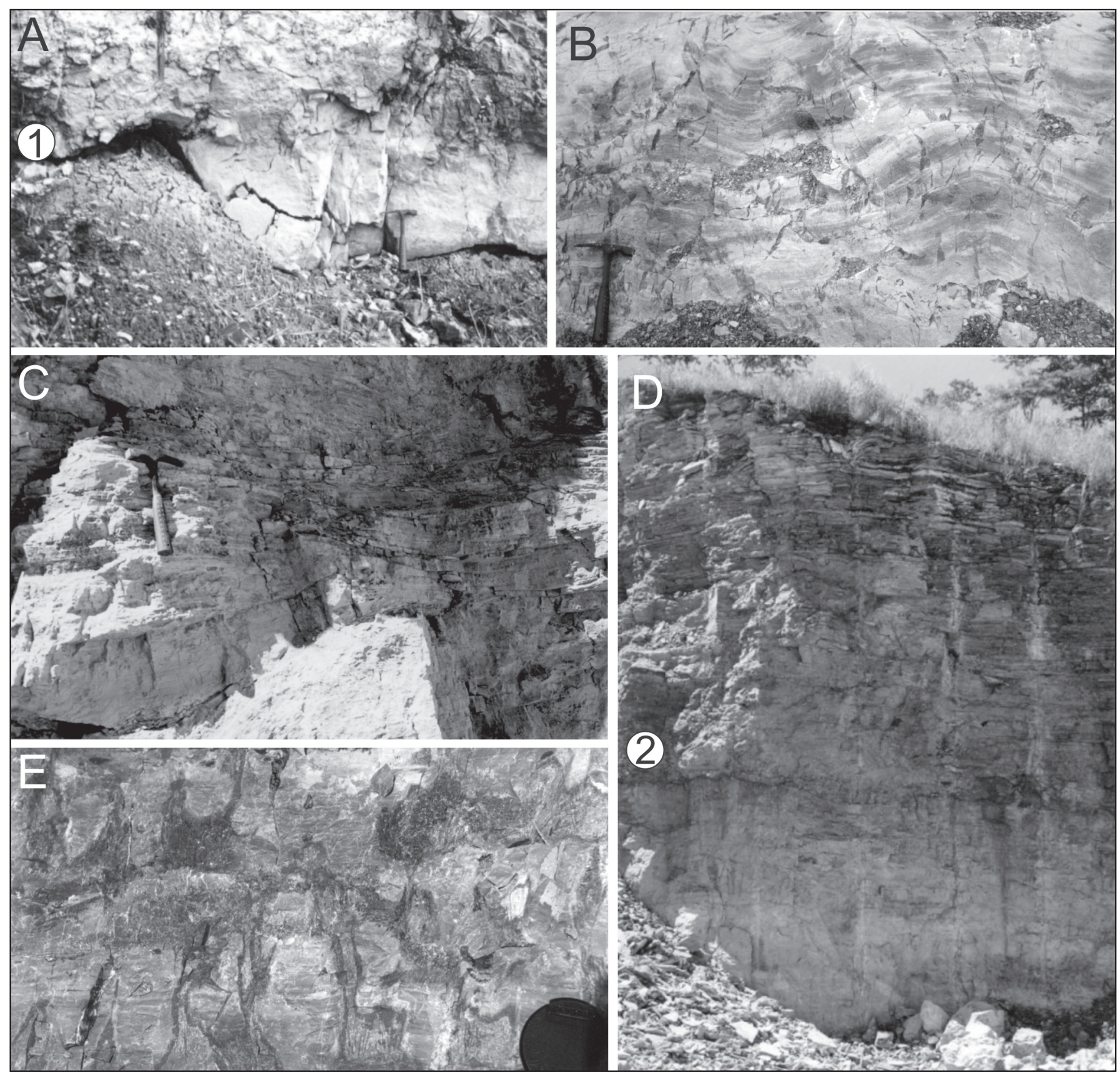

Figura 5. Fácies das formações Mirassol d'Oeste e Guia. (A) Estrutura de sobrecarga sobre diamictito definindo contato 1, (B) estromatólito estratiforme, (C) estrutura tipo tepee, (D) contato 2 entre as formações Mirassol d'Oeste e Guia; e (E) leques de cristais de calcita (pseudomorfos de aragonita) seccionando calcário fino.

de dezenas de metros, lateralmente contínuas por centenas de metros (Fig. 4). Grãos terrígenos (quartzo, feldspato, mica e minerais pesados), subarredondados, de tamanho silte a areia fina, ocorrem disseminados ou concentrados na base das camadas, localmente constituindo acamamento gradacional. Faixas milimétricas de calcário impregnadas por betume que preenche porosidade intercristalina alternam-se com o micrito e crostas calcíticas, fornecendo um padrão visual listrado ao carbonato, com tonalidades claras e escuras (Nogueira \& Riccomini 2001b). As várias formas de crostas e cristais fibrosos alongados, com hábito pseudo-hexagonal e acicular, formando feixes ou leques de até $10 \mathrm{~cm}$ de altura sugerem aragonita como primeira fase de precipitação (Fig. 5E). Os arranjos em paliçada e mamiliforme dos cristais são similares àqueles descritos por James et al. (2001) para a sucessão da capa carbonática Ice Brook no Ca- nadá e caracterizam as capas calcárias tipo cementstones (e.g. Hoffman \& Shrag 2002), de cristais fibrosos, Na Faixa Paraguai Norte, a base da Formação Guia é desprovida de crostas e cristais, predominando calcários finos e folhelhos, por vezes dolomitizados (Fig. 3). Camadas com deformação sinsedimentar são restritas a intervalos estratigráficos distintos, caracterizadas por diques netunianos, estruturas de slump, fraturas, falhas normais e de cavalgamento, geralmente preenchidas por calcita macrocristalina (Fig. 4).

As camadas de calcário fino e folhelho do topo da Formação Guia alcançam espessuras de até $3 \mathrm{~m}$, muitas vezes formando ritmitos (fácies de ritmito de Boggiani 1997) (Fig. 6, 7). A abundância de planos de estilolitização paralelos ao acamamento muitas vezes forma pseudo-estratificação (fitted fabric). Cristais autigênicos de pirita e lentes centimétricas de calcário cristalino 


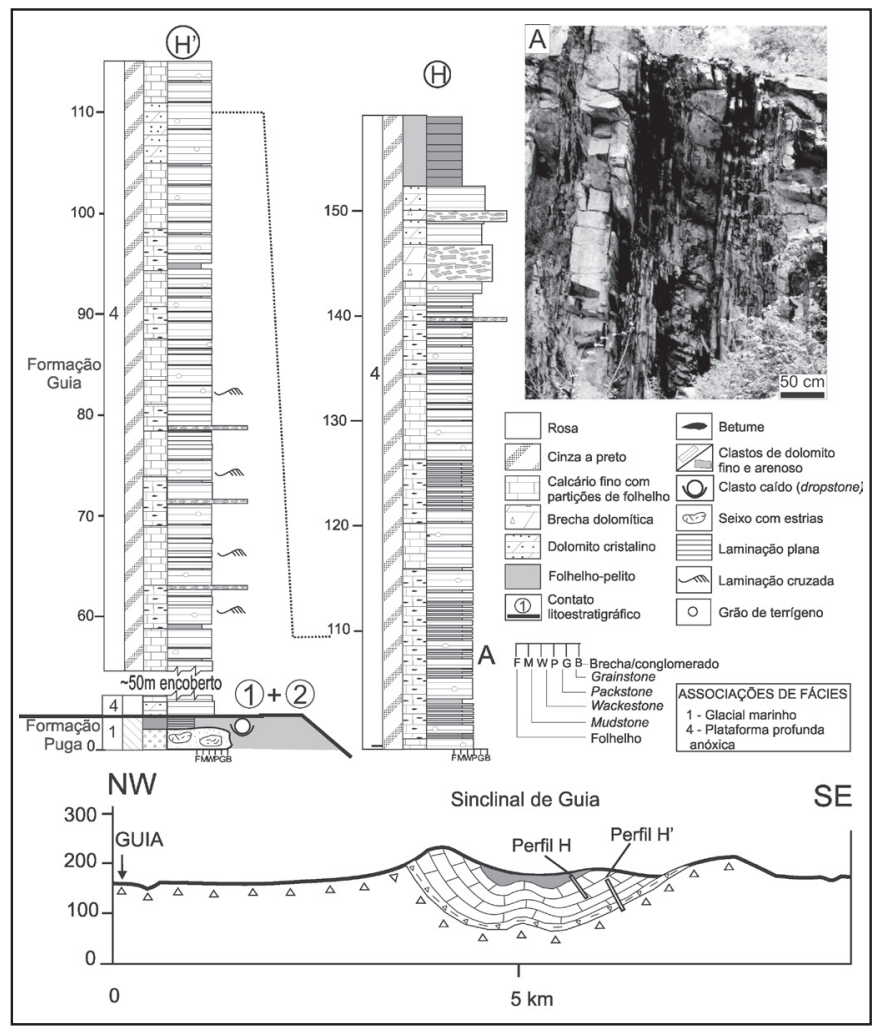

Figura 6. Holoestratótipo da Formação Guia, mina Nossa Senhora da Guia. Calcário fino e folhelho intercalados (foto A) são interpretados como depósitos de plataforma profunda anóxica.

com laminação cruzada ocorrem esporadicamente. No hipoestratótipo da seção da mina Emal-Camil, o limite superior desta unidade é recoberto por brechas dolomíticas da Formação Serra do Quilombo (Fig. 7). Camadas de dolomitos com dezenas de metros de espessura são observadas nas minas Nossa Senhora da Guia e principalmente em Itaipu.

Calcários finos sem estruturas produzidas por ondas e correntes de maré, com camadas planas, contínuas por quilômetros, são compatíveis com sedimentação em uma extensa plataforma, em zona de baixa energia e abaixo da base das ondas de tempestade (Stow 1986, Coniglio \& James 1990). A cor escura dos calcários e a presença de folhelhos betuminosos e pirita revelam a predominância de condições de anoxia e estagnação, que proporcionaram o acúmulo e preservação da matéria orgânica. As lâminas de cimento fibroso isópaco e leques de cristais originalmente aragoníticos, preservados como pseudomorfos de calcita (cf. Tucker 1992), apontam em grande parte para a precipitação direta no assoalho marinho profundo, acompanhando a acumulação carbonática em ambiente provavelmente supersaturado em aragonita, típico dos mares pré-cambrianos (Grotzinger \& Knoll 1995, Sumner \& Grotzinger 1996).

Camadas brechadas e deformadas podem ser relacionadas com o intumescimento do assoalho marinho causado pela concomitante cimentação e cristalização expansiva sinsedimentar (Kennedy 1996). A associação de falhas, estruturas de slumping, fluxo de massa, diques netunianos e brechas sugere progressiva ruptura e deformação plástica de camadas, ressedimentação e eventos de cimentação sinsedimentar. Estas instabilidades gravitacionais em sedimentos parcialmente litificados são aqui interpretadas como geradas em águas profundas, possivelmente relacionadas à declividade de uma rampa no assoalho marinho. Correntes de turbidez podem ter gerado a gradação normal encontrada nas camadas de calcário fino, separadas por intervalos

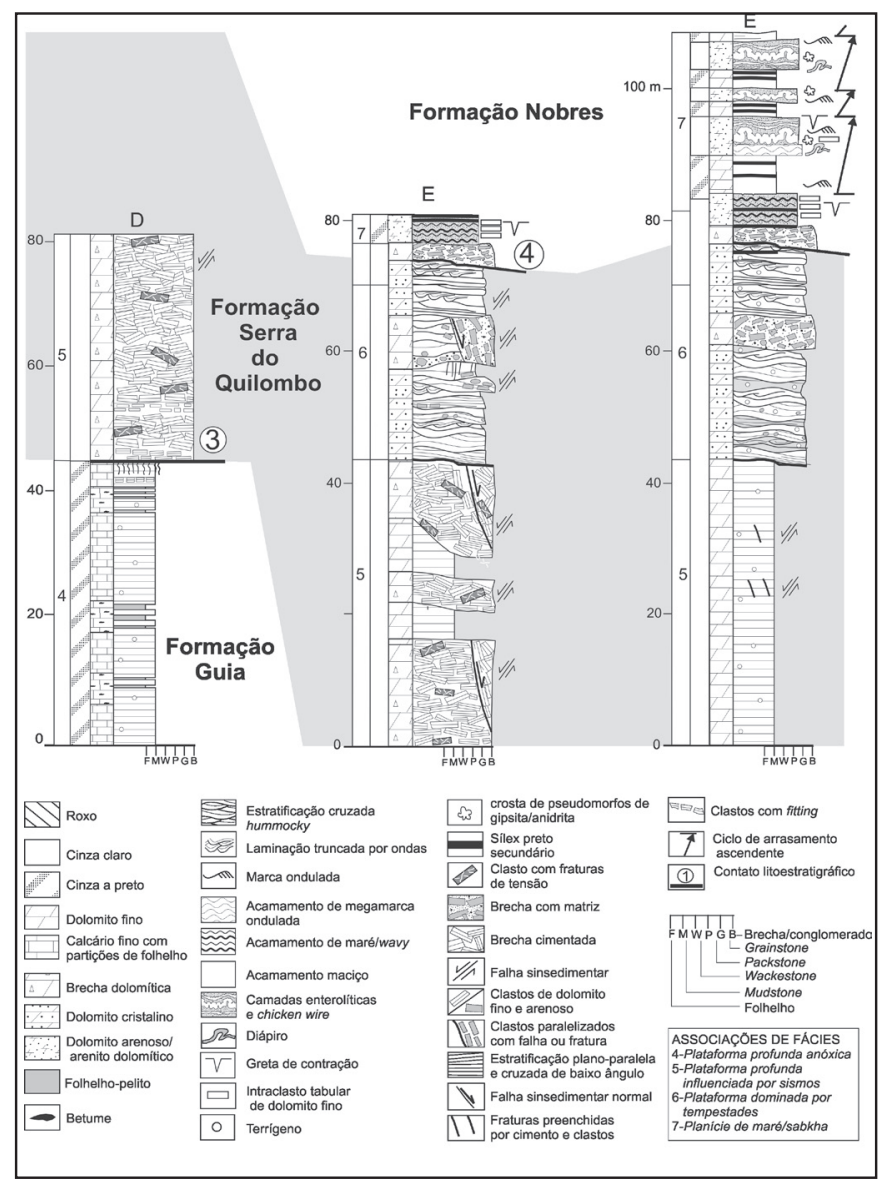

Figura 7. Holoestratótipo da Formação Serra do Quilombo, mina da Camil/Emal, região de Cáceres.

de suspensão (partições de folhelho), o que é coerente com a inferência de um paleoambiente marinho profundo. Intervalos de deformação intercalados com camadas sem perturbação e estruturas com diferentes estilos de deformação (rúptil e plástica) podem ser atribuídas a eventos de choques sísmicos (Obermeier et al. 1985, Kahle 2002). Processos de dissolução por pressão resultaram na formação da pseudo-estratificação e a intensa dolomitização heterogênea afetou pacotes métricos de calcários finos comuns à base e porções do topo da Formação Guia. As camadas de dolomitos em contato com os diamictitos na Formação Puga, encontradas na região da Faixa Paraguai, não são capas carbonáticas. Apesar do sinal isotópico negativo de ${ }^{13} \mathrm{C}$ (Alvarenga et al. 2004), estas camadas foram formadas por dolomitização do calcário fino e não exibem as estruturas típicas de uma capa carbonática (cf. Hoffman \& Shrag 2000).

FORMAÇÃO SERRA DO QUILOMBO As melhores exposições da Formação Serra do Quilombo encontram-se na Mina Emal/ Camil, situada na região de Cáceres, porção SE da Serra do Quilombo, sendo considerada como holoestratótipo desta unidade (Fig. 7). Seções de referência podem ser observadas na mina abandonada na entrada sul da cidade de Nobres e na Mineração Itaipu, em Bauxi (Fig.1).

A zona de contato entre as formações Guia e Serra do Quilombo é marcada por intenso fraturamento nos dolomitos e calcários finos associados com brechas cimentadas por dolomita (Fig. 7, 8A, 8B). As brechas formam acumulações descontínuas, com espessuras de 2 até mais de $30 \mathrm{~m}$ de espessura, se intercalam com dolomito fino laminado ou apresentam contato lateral brusco com este, provavelmente por falhas sinsedimentares. Os 
clastos de dolomito fino, com até $30 \mathrm{~cm}$ de eixo maior, possuem arcabouço aberto e são cimentados por dolomita espática (mosaico equidimensional drusiforme). Muitas vezes, as brechas exibem clastos com perfeito ajuste (fitting), sendo possível reconstituir a camada fraturada (Fig. 7B).

A parte superior da Formação Serra do Quilombo apresenta camadas com espessuras centimétricas a métricas de dolomito grosso (dolomito cristalino) (Fig. 7). Partículas carbonáticas não são discerníveis nos afloramentos e nem em lâminas petrográficas. Ao microscópio são observados apenas cristais de dolomita com tamanho acima de 4 a $10 \mu$, e, às vezes, podem formar agregados (fantasmas de pelóides?). O dolomito exibe até 20\% de grãos terrígenos na fração silte a areia fina (quartzo, feldspato e mica). A estratificação plano-paralela associa-se com a estratificação cruzada hummocky, de até $3 \mathrm{~m}$ de comprimento e amplitude de $0,5 \mathrm{~m}$, formando bancos amalgamados em sucessões de até $5 \mathrm{~m}$ de espessura. As marcas onduladas são simétricas e assimétricas e a laminação cruzada exibe uma variedade de feições diagnósticas da atuação de ondas (De Raaf et al. 1977), tais como base erosiva e padrão das lâminas em chevron (Fig. 8C).

Os dolomitos grossos arenosos (dolomito cristalino areno- so) com estruturas internas gradam para camadas de brechas. Esta passagem lateral é dada por camadas fraturadas (mas com fitting), rotacionadas e falhadas, que se desarticulam e formam pacotes métricos de brechas (Fig. 7). Os clastos são de dolomito grosso arenoso e, subordinadamente, de cálcario fino preto, com tamanhos que variam de seixo até matacão.

Os dolomitos finos representam deposição de baixa energia, abaixo da base de ondas de tempestade, em plataforma carbonática. Nas brechas intraformacionais, clastos, matriz e grande parte do cimento são geneticamente relacionados. As brechas não apresentam feições de slumping ou de fluxo de detritos como aquelas descritas por Nemec \& Steel (1984). Tanto em ambiente continental quanto em ambiente marinho, brechas formadas in situ têm sido interpretadas como resultado de sismicidade (Zanchi 1992, Kahle 2002). Logo após o fraturamento, a porosidade foi preenchida por cimento que inibiu as compactações mecânica e química. A continuidade lateral destes depósitos deformados por muitos quilômetros de distância, como na região de Nobres (hipoestratótipo), e sua intercalação com depósitos sem deformação são consistentes com uma causa alocíclica associada à sismicidade.
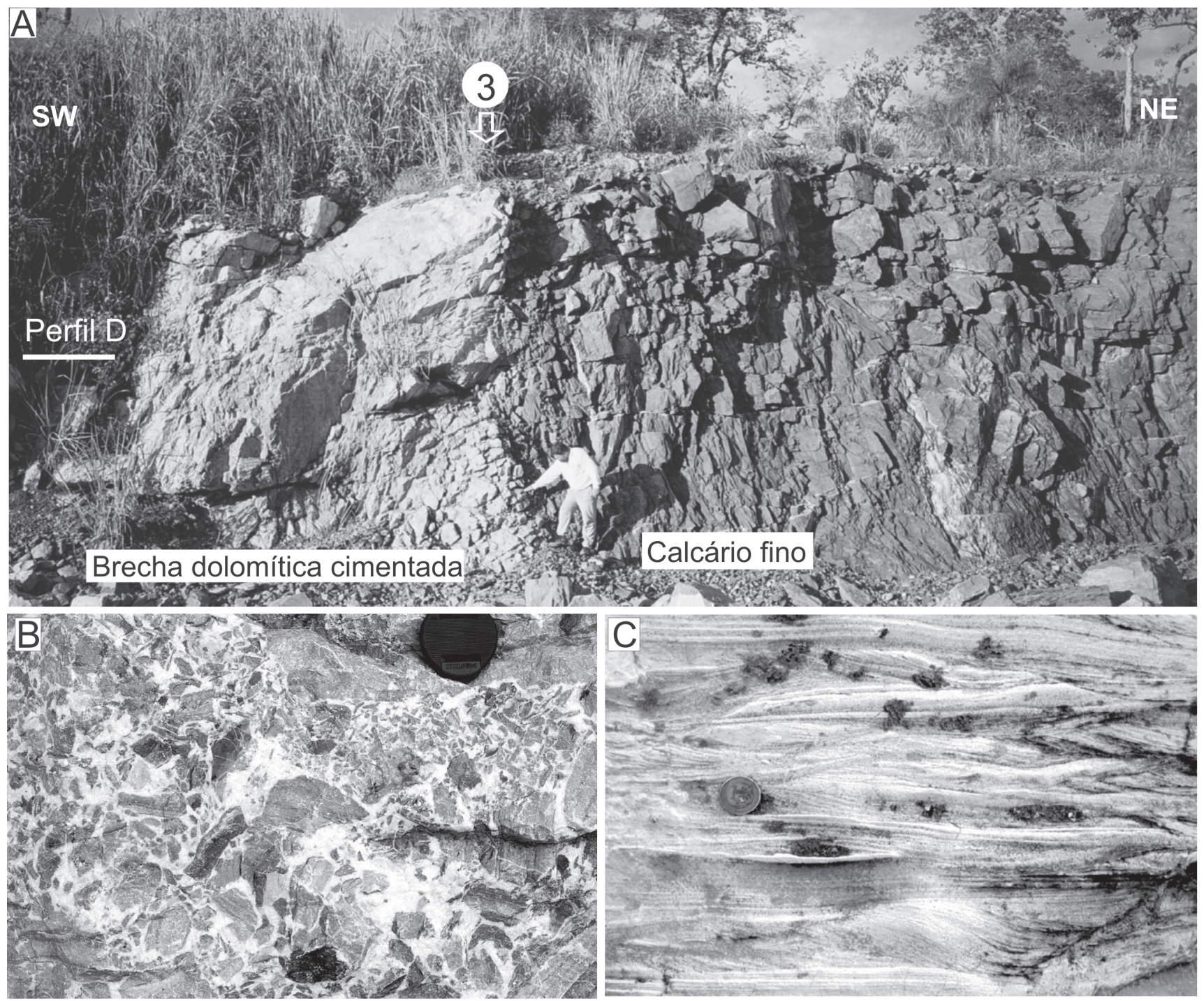

Figura 8. (A) Contato litoestratigráfico 3 entre as formações Guia e Serra do Quilombo; (B) brecha dolomítica com clastos tabulares com fitting e cimentados por dolomita espática; e (C) laminação cruzada com padrão em chevron associada à laminação quase - planar. 
A atuação de tempestades em depósitos de face litorânea superior é indicada pela presença de estratificação cruzada hummocky. A presença desta estrutura sugere uma área extensa de geração ( fetch) de tempestades, em região tropicalequatorial (cf. Barron 1986), compatível com uma plataforma carbonática com conexão oceânica. As camadas planas (flat beds) são interpretadas como produto de fluxo oscilatório de alta velocidade, em regime de fluxo superior, com predominância da componente unidirecional (cf. Cheel \& Leckie 1993). No declínio do fluxo gerado por tempestades, o fundo marinho foi retrabalhado por ondas.

A transição lateral e vertical de dolomitos finos e dolomito grosso arenoso para brechas com clastos e matriz maciça, sugere brechação in situ. As brechas podem ser resultantes da liquefação parcial de um carbonato argiloso sob efeito da carga induzida por ondas cíclicas durante tempestades tropicais (Bouchette et al. 2001). Assim como as ondas de tempestades, os terremotos também geram stress cisalhante, que cria um progressivo aumento da pressão nos poros das camadas que leva ao escape dos fluídos e à formação de estruturas de deformação (Obermeier et al. 1985). Desta forma, ambos os processos, de tempestades e sismicidade, podem ter atuado na deposição da parte superior da Formação Serra do Quilombo.

FORMAÇÃO NOBRES O holoestratótipo da Formação Nobres encontra-se no km 698 da rodovia BR-070 (Fig. 9), enquanto a sucessão encontrada na Mina Emal/Camil, situada na região de Cáceres, é um paraestratótipo que encerra a parte basal da formação (Fig. 7). O paraestratótipo que encerra a parte superior da formação é encontrado no km 698 da rodovia BR-070 (Fig. 9). O melhor hipoestratótipo é encontrado na Mina de Copacel em Nobres (Fig. 1, 3). Os depósitos da Formação Nobres que ocorrem por mais de $300 \mathrm{~km}$ de extensão na parte norte da Faixa Paraguai, estão organizados em ciclos métricos tabulares, lateralmente contínuos por centenas de metros. Neste artigo o termo "Nobres" (Hennies 1966), que anteriormente designava a unidade dolomítica do Grupo Araras, é aplicado apenas aos depósitos dolomíticos organizados em ciclos métricos com abundância de sílex secundário (Fig 7,9). O contato com a Formação Serra do Quilombo é irregular e marcado pela ocorrência de brechas e arenitos com clastos tabulares de micrito e gretas de contração (Fig. 7).

A parte inferior da Formação Nobres é caracterizada pela predominância de ciclos formados por: 1) dolomito fino (dolomudstone) e 2) dolomito arenoso e brecha intraclástica dolomítica (dolorudstone intraclástico) (Fig. 7). O dolomito fino forma camadas maciças e/ou laminadas de até $5 \mathrm{~m}$ de espessura, cuja base desenvolve um contato brusco com o ciclo subjacente, enquanto que a passagem superior para os dolomitos arenosos com camadas enterolíticas é geralmente transicional. As camadas enterolíticas são complexas, geralmente associadas a moldes de evaporitos e estrutura chicken-wire e nodular, algumas vezes rompidas e dobradas por estruturas de injeção ou diapíricas (Fig. 10A). O dolomito arenoso apresenta cristais finos a grossos associados a grãos terrígenos e intraclastos tabulares de dolomito fino de até $3 \mathrm{~cm}$ de comprimento. Os grãos terrígenos (quartzo, feldspato, mica, fragmentos vulcânicos) são geralmente de tamanho areia fina a grossa, ocorrendo grânulos subordinadamente. Apresentam-se subarredondados a arredondados, contrastando com os intraclastos. Dolomitos arenosos com acamamento heterolítico, formado por laminações onduladas e deformadas, formam pacotes de até $4 \mathrm{~m}$ de espessura. $\mathrm{O}$ acamamento ondulado (marca ondulada e acamamento wavy de $\lambda=7$ a $14 \mathrm{~cm}, \mathrm{H}=0,3 \mathrm{a} 1,0 \mathrm{~cm}$ e megamarca ondulada de $\lambda=15 \mathrm{a}$ $37 \mathrm{~cm}$ e $\mathrm{H}=2$ a $5 \mathrm{~cm}$ ) geralmente é destacado por recobrimentos de dolomito fino.
Os ciclos métricos da porção superior da Formação Nobres são formados por: 1) dolomito fino (dolomudstone) e subordinadamente dolomito oolítico (dolopackstone/dolograinstone oolítico) na base; e 2) dolomito fino com estromatólitos (doloboundstone microbiano), dolomito arenoso e brecha com intraclastos (dolopackstone e rudstone intraclástico) na parte superior (Fig. 10B). Os estromatólitos são formados por lâminas de 1-2 mm de espessura; quando substituídas por sílex, essas lâminas são ressaltadas em alto relevo. Três morfologias de estromatólitos foram observadas: 1) dômica a estratiforme; 2) estratiforme; e 3) rugosa. O tipo dômico a estratiforme é o mais comum nos ciclos da Formação Nobres. Apresenta um padrão ondulatório tridimensional, formando uma morfologia externa de hemiesferas, com até $10 \mathrm{~cm}$ de diâmetro e $5 \mathrm{~cm}$ de altura, ligadas lateralmente por alguns metros (Fig. 10C). Os outros dois tipos ocorrem próximo ao contato com os depósitos siliciclásticos da Formação Raizama. O tipo estratiforme a suavemente ondulado se caracteriza pelo desenvolvimento de cavidades fenestrais irregulares ou birds eyes e laminação fenestral. O tipo rugoso lembra o aspecto de cérebro, recobre horizontes brechados e de tepees, e associa-se a crostas substituídas por sílica com morfologia tipo "pipoca" interpretadas como moldes de cristais evaporíticos (Fig. 10D). Arenitos dolomíticos, com camadas de até $70 \mathrm{~cm}$ de espessura, exibem acamamento heterolítico, e camadas exclusivamente de arenito fino a médio alcançam até 5 $\mathrm{cm}$ de espessura, geralmente com topos planos ou com marcas onduladas recobertas por lâminas de dolomito fino. Os níveis de dolomito fino podem ser contínuos ou descontínuos e, na maioria das vezes, encontram-se fraturados formando brechas com

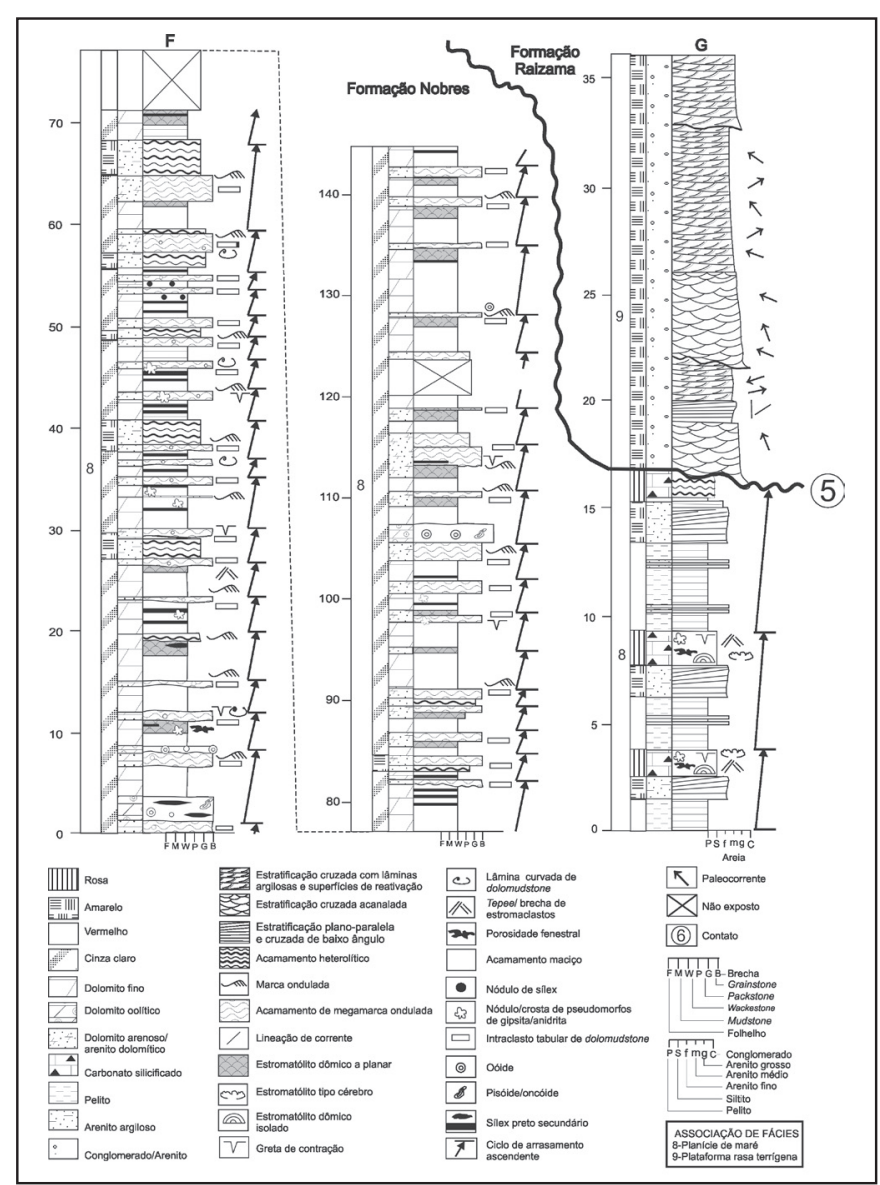

Figura 9. Holoestratótipo e paraestratótipo da Formação Nobres, km 698 (perfil F) e 690 (perfil G), respectivamente, da rodovia BR-070). 

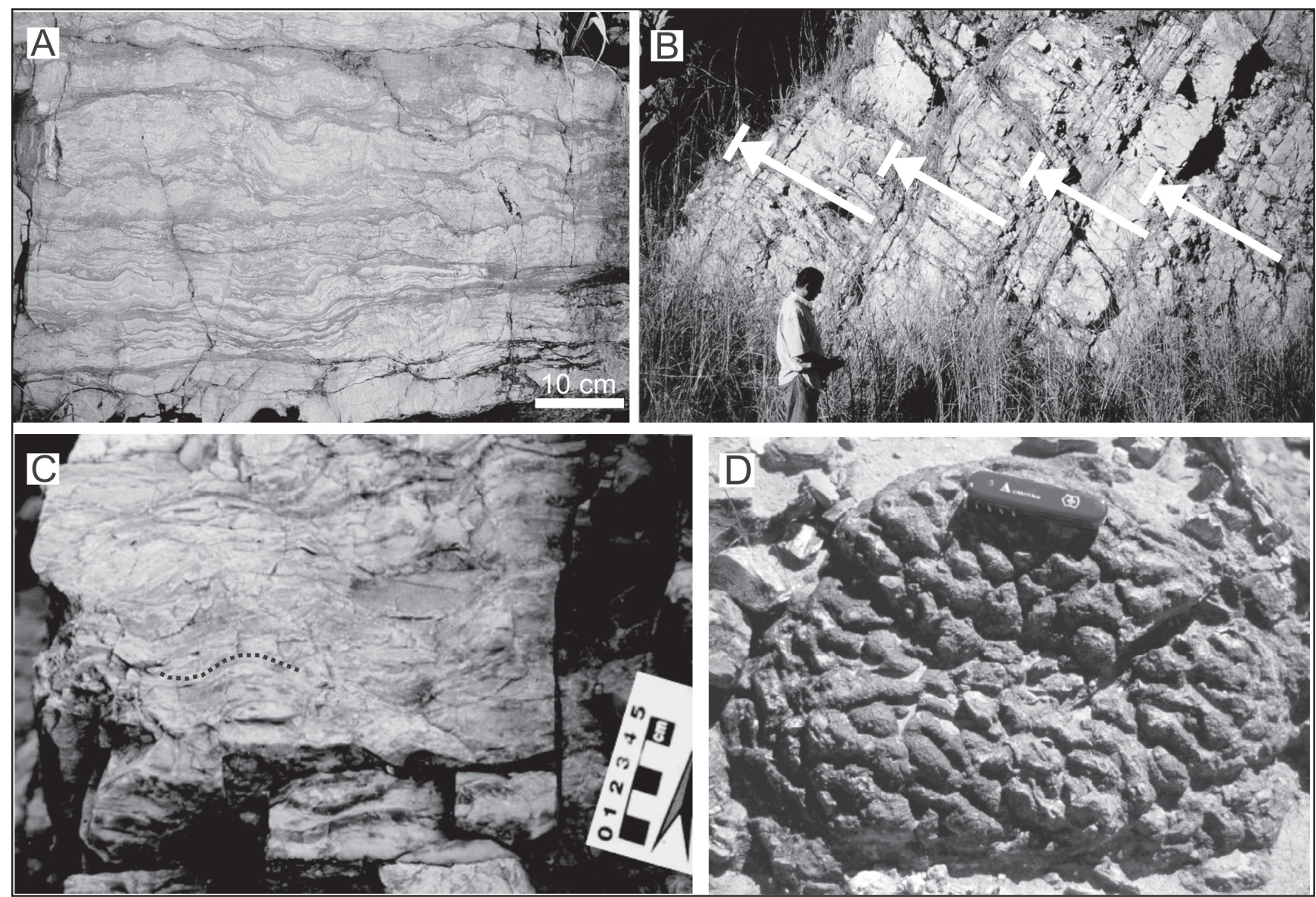

Figura 10. Fácies da Formação Nobres. (A) Camadas deformadas enterolíticas; (B) Ciclos formados por dolomitos finos e arenosos da porção superior; (C) estromatólito dômico; (D) estromatólito rugoso com aspecto de cérebro.

clastos tabulares e recurvados (1 a $3 \mathrm{~cm}$ de tamanho), algumas vezes com topo marcado por concentração de nódulos de sílex e gretas de contração.

Nos ciclos próximos ao contato erosivo com as rochas siliciclásticas da Formação Raizama, do Grupo Alto Paraguai, em lugar dos dolomitos finos ocorrem pacotes de pelitos finamente laminados, com espessuras de até $3 \mathrm{~m}$, que podem se intercalar com níveis centimétricos de arenitos finos e carbonatos silicificados (Perfil G da Fig. 9).

Os ciclos observados na base da Formação Nobres são interpretados como uma sucessão de arrasamento e salinização ascendente (shallowing upward e brining upward), relacionada aos ambientes de inframaré (dolomudstone maciço a laminado) e intermaré/supramaré (ritmito dolomudstone/dolomito arenoso). As lamas carbonáticas foram precipitadas sob condições de energia baixa a moderada, provavelmente em ambiente lagunar. Camadas nodulares e complexamente contorcidas (enterolíticas), estruturas tipo chicken wire e nódulos de sílex são comumente relacionados a ambientes evaporíticos de planície de supramaré/sabkha (Tucker 1992, Kendall \& Harwood 1996). Camadas nodulares e enterolíticas são formadas pelo contínuo crescimento de anidrita dentro do sedimento ou devido à substituição das crostas de gipsita por anidrita durante altas temperaturas, causado a expansão, ruptura, dobramento e deslocamento ascendente de camadas na forma de diápiros (Hardie \& Shinn 1986). Posteriormente, estas feições foram afetadas por processos de silicificação e dolomitização.

Os ciclos do topo da Formação Nobres possuem maior influxo de siliciclásticos e são também relacionados a sucessivas progradações de planície de maré e inframaré em clima árido.

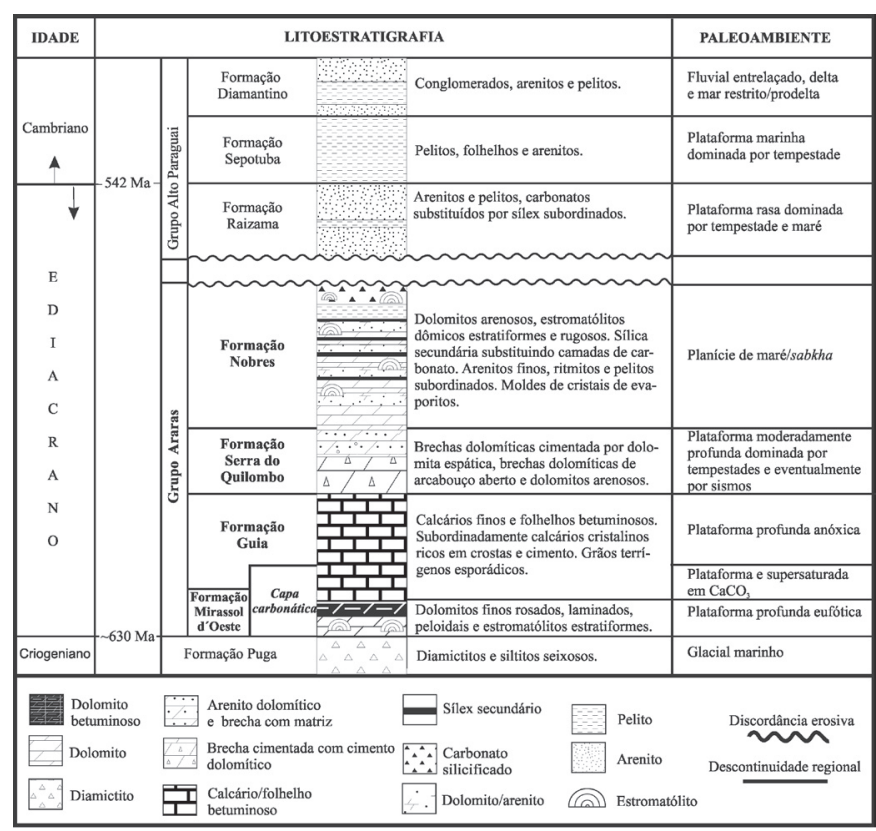

Figura 11. Quadro geral da litoestratigrafia do Grupo Araras.

Barras oolíticas migravam induzidas por correntes moderadas em áreas de profundidades mais rasas de inframaré. A freqüência de acamamento heterolítico, que indica alternância de processos trativos e de suspensão, associado com brechas intraformacio- 
nais, níveis com gretas de ressecação, nódulos de sílex e moldes, interpretados como cristais de evaporitos, indicam eventos de exposição subaérea, num ambiente hipersalino a misto, característico da zona de intermaré superior a supramaré (cf. Pratt et al. 1992). Esta zona foi caracterizada pela atividade microbiana, cujas esteiras tornaram-se corrugadas por desenvolverem-se em um substrato composto de brechas de sais, estromaclastos e estruturas tepee. A presença de nódulos de evaporitos silicificados e de crostas com morfologia de pipoca típica de halita (e.g. Goodall et al. 2000) caracterizam um paleoambiente hipersalino e árido sob condições de temperaturas acima de $35^{\circ} \mathrm{C}$. Estas condições climáticas prevaleceram durante o início da deposição siliciclástica da Formação Raizama que apresenta depósitos de maré e tempestades em clima tropical (Nogueira \& Riccomini 2004). Esta interpretação vem de encontro com os dados paleomagnéticos obtidos para o Grupo Araras, que indicam um movimento lento do Cráton Amazônico entre 600 e 520 Ma, sempre em baixas latitudes (Trindade et al. 2003).

A leitura faciológica do Grupo Araras ofereceu uma nova concepção litoestratigráfica para os depósitos carbonáticos da Faixa Paraguai Norte (Figura 11), fornecendo subsídios importantes para desvendar sua evolução paleoambiental e contextualizar seus estratos nos intervalos críticos da biosfera neoproterozóica.

CONCLUSÕES O Grupo Araras foi subdividido em quatro formações, da base para o topo: 1) Mirassol d'Oeste, que consiste em dolomito fino rosado e estromatólitos; 2) Guia, composta de calcário fino intercalado com folhelhos, localmente betuminosos, com abundância de crostas e cristais de calcita, e brechas calcárias subordinadas; 3) Serra do Quilombo, constituída por dolomito fino, brecha dolomítica e dolomito arenoso; e 4) For- mação Nobres, encerrando dolomitos finos, dolomitos arenosos, oolíticos, arenitos e pelitos, geralmente substituídos ou intercalados com níveis de sílex secundário.

A análise de fácies sugere que o ambiente deposicional do Grupo Araras variou de plataforma carbonática, moderadamente profunda a rasa, influenciada por eventos de supersaturação em $\mathrm{CaCO}_{3}$, sísmicos e de tempestades (Formações Mirassol d'Oeste, Guia e Serra do Quilombo) e plataforma carbonática rasa caracterizada por ambientes de sabkha e planície de maré (Formação Nobres).

Após o evento de snowball Earth, marcado pelos diamictitos marinoanos da Formação Puga, o clima quente prevaleceu durante toda a deposição da plataforma carbonática Araras. Estas condições continuaram durante a deposição siliciclástica da Formação Raizama (Grupo Alto Paraguai), ou seja, as glaciações não retornaram mais na região sul do Cráton Amazônico no Ediacarano.

A redefinição e redescrição do Grupo Araras permitiram a retomada da hierarquia de grupo proposta por Almeida (1964) para as rochas carbonáticas Araras da Faixa Paraguai Norte, bem como consolidou as designações "Guia" e "Nobres" de Hennies (1966). Além disso, o trabalho reconheceu a importância do Grupo Araras no contexto dos eventos anômalos globais do final do Neoproterozóico.

Agradecimentos Os autores externam seus agradecimentos à Fundação de Amparo à Pesquisa do Estado de São Paulo (FAPESP) pelo suporte financeiro (Processo 00/02903-8, para C. Riccomini), Coordenação de Aperfeiçoamento de Pessoal do Ensino Superior (CAPES) pela concessão de bolsa (doutorado para A.C.R. Nogueira) e aos revisores da Revista Brasileira de Geociências pelas sugestões apresentadas.

\section{Referências}

Allen P.A. \& Hoffman P.F. 2004. Extreme winds and waves in the aftermath of a Neoproterozoic glaciation. Nature, 433:123-127.

Almeida F.F.M. 1964. Geologia do Centro-Oeste Matogrossense. Boletim da Divisão de Geologia e Mineralogia. DNPM, 219, p. 1-53

Almeida F.F.M. 1965. Geossinclíneo Paraguaio. In: Semana de Debates Geológicos, 1, Porto Alegre. Centro Acad. Est. Geol, p. 88-109.

Almeida F.F.M. 1967. Nota sobre o Pré-Cambriano na região central de Goiás. Bol. Paran. de Geociênc., 26:19-22.

Almeida, F.F.M. 1974. Antefossa do alto Paraguai. In: SBG, Cong. Bras. Geol., 28, Porto alegre. Anais, v.4, p.3-6.

Almeida F.F.M. 1984. Província Tocantins, setor sudoeste. In: F.F.M. Almeida \& Y. Hasui (Coords) O Pré-Cambriano do Brasil. São Paulo, Ed. Blücher Ltda, pp.: 265-281.

Almeida F.F.M. \& Mantovani M.S.M. 1975. Geologia e geocronologia do Granito de São Vicente, Mato Grosso. An. Acad. Bras. Ciênc., 47:451-458.

Alvarenga C.J.S. 1988. Turbiditos e a glaciação do .nal do Proterozóico Superior no Cinturão dobrado Paraguai, Mato Grosso. Rev. Bras. Geoc., 18:323-327.

Alvarenga C.J.S. 1990. Phénomènes sédimentaires, structuraux et circulation de fluides développés à la transition chaîne-craton. Exemple de chaîne Paraguai d'age protérozoïque supérieur, Mato Grosso, Brésil. Thèse doct. Univ. Aix-Marseille III, 177 p.

Alvarenga C.J.S. \& Saes G.S. 1992. Estratigrafia e sedimentologia do Proterozóico Médio e Superior da região sudeste do Cráton Amazônico. Rev. Bras. Geoc., 22:493-499.

Alvarenga C.J.S. \& Trompette R. 1993. Evolução tectônica brasiliana da Faixa Paraguai: a estruturação da região de Cuiabá. Rev. Bras. Geociênc., 23:18-30.

Alvarenga C.J.S. \& Trompette R. 1994. A Faixa Paraguai e sua compartimentação estratigráfica e tectônica. In: SBG, Cong. Bras. Geol., 38,
Camboriú. Anais, v.1, p.239-240.

Alvarenga C.J.S., Santos R.V., Dantas E.L. 2004. C-O-Sr isotopic stratigraphy of cap carbonates overlying Marinoan-age glacial diamictites in the Paraguay Belt, Brazil. Precambrian Research, 131:1-21.

Barron A.J. 1989. Severe storms during Earth history. Geol. Soc. Am. Bull., 101:601-612.

Barros A.M. \& Simões M.A. 1980. Levantamento geológico nas porções meio-leste da Folha SD.21-Z-A e extremo noroeste da Folha SD.21Z-C, abrangendo áreas dos Municípios de Raizama, Rosário Oeste, Nobres e Diamantino; operação 511/80. Goiânia, Projeto RADAMBRASIL, Relatório Interno $\mathrm{n}^{\circ}$ 387-G, 31p.

Barros A.M., Silva R.H., Cardoso O.R.F.A., Freire A.F., Souza JR, J.J., Rivetti M., Luz D.S., Palmeira R.C.B., Tassinari C.C.G. 1982. Geologia da Folha SD.21-Cuiabá. Rio de Janeiro, Projeto Radambrasil, DNPM, Levantamento de Recursos Naturais, 26, p. 25-192.

Basei M.A.S. \& Brito Neves B.B. 1992. Características geológicas da transição Proterozóico-Faneorozóico no Brasil. In: J.G. Gutierrez Marco \& I. Rábano (Eds.) Paleozoico Inferior de Iberoamérica. Mérida, Universidad de Extremadura. p.: 331-342.

Boggiani P.C. 1997. Análise estratigráfica da bacia Corumbá (Neoproterozóico)

- Mato Grosso do Sul. Tese de Doutoramento, Instituto de Geociências, Universidade de São Paulo, São Paulo, 181p.

Bonhomme M.G., Cordani U.G., Kawashita K., Macedo M.H.F., Thomas Filho A. 1982. Radiochronological age and correlation of Proterozoic sediments in Brazil. Precamb. Res., 18:103-118.

Bouchette F., Séguret M., Moussine-Pouchkine A. 2001. Coarse carbonate breccias as a result of water-wave cyclic loading (Uppermost Jurassic- South-East Basin, France). Sedimentology, 48:767-789.

Castelneau F. 1850. Expedition dans les parties centrales de l'Amérique $d u$ Sud. Histoire du Voyage, Paris. Libraire Editeur, Tomo II., 485p. 
Cheel R.J. \& Leckie D.A. 1993. Hummocky cross-stratification. In: V.P. Wright (Ed.) Sedimentology Review. Cambridge, Blackwell Scientific Publication, p.103-122.

Coniglio M. \& James N.P. 1990. Origin of fine-grained carbonate and siliciclastic sediments in an early Palaeozoic slope sequence, Cow Head Group, western Newfoundland. Sedimentology, 37:215-230.

Cordani U.G., Kawashita K., Thomaz Filho A. 1978. Applicability of the rubidium-strontium methods to shales and related rocks. In: G.V. Cohee, M.F. Glaessner, H.D. Hedberg (Eds.) Contributions to the geologic time scale. Am. Assoc. Petrol. Geol., Studies in Geologie, 6, p. 93-117.

Cordani U.G., Thomaz Filho A., Brito Neves B.B., Kawashita K. 1985. On the applicability of the Rb-Sr method to argillaceous sedimentary rocks: some examples from Precambrian sequences of Brazil. Giornale Geol., 471:253-280.

Correa J.A. \& Couto E.A. 1972. Projeto aluviões diamantiferos de Mato Grosso. Relatório Final. Goiânia, DNPM-CPRM. 2v. (Relatório do Arquivo Técnico da DGM, 1940).

Corsetti F.A. \& Hagadorn J.W. 2002. Precambrian-Cambrian transition: Death valley, United States. Geology, 28:299-302.

Dalziel I.W.D. 1992. On the organization of American plates in the Neoproterozoic and the breakout of Laurentia. GSA Today, 2:240- 241.

De Raaf J.F.M., Boersma J.R., Van Gelder A. 1977. Wave-generated structures and sequences from a shallow marine succession, Lower Carboníferous, County Cork, Ireland. Sedimentology, 24:451-483.

Del'Arco J.O., Silva R.H., Tarapanoff I., Freire F.A., Pereira L.G.M., Souza S.L., Luz L.G., Palmeira R.C.B., Tassinari C.C.G. 1982. Geologia da Folha SE.21 Corumbá e parte da Folha SE.20. Rio de Janeiro. Projeto RADAMBRASIL, MME, Levantamento de Recursos Naturais, n. 27, p.25-160.

Dunham R.J. 1962. Classification of carbonate rocks according to depositional texture. In: W.E. Ham (Ed.) Classification of Carbonate rocks. Am. Ass. Petrol. Geol., p.108-121 (Memoir 1).

Evans J.W. 1894. The Geology of Mato Grosso, particularly the region drained by the upper Paraguay. Quart. J. Geol. Soc. London, L:85104.

Figueiredo A.J.A. \& Olivatti O. 1974. O projeto Alto - Guaporé. Goiânia, DNPM/ CPRM, Relatório do arquivo técnico da DGM, n. 2323 , $11 \mathrm{v}$.

Folk R.L. 1974. Petrology of sedimentary rocks. Austin, Hemphill Publishing, 182p.

Gaucher C., Boggiani P.C., Sprechmann P., Sial A.N., Fairchild T. 2003. Integrated correlation of the Vendian to Cambrian Arroyo del Soldado and Corumbá Groups (Uruguay and Brazil): palaeogeographic, palaeoclimatic and palaeobiologic implications. Precamb. Res., 120:241-278

Goodall T.M., North C.P., Glennie K.W. 2000. Surface and subsurface sedimentary structures produced by salt crusts. Sedimentology, 47:99-118

Grotzinger J.P.S. \& Knoll A.H. 1995. Anomalous carbonate precipitates: is the Precambrian the key to the Permian? Palaios, 10:578-596.

Guimarães G. \& Almeida L.F.G. 1972. Projeto Cuiabá. Cuiabá, DNPM, Relatório do arquivo técnico da DGM, n. 1872.

Hahn G., Hahn R., Plfug H.D., Leonardos O.H., Walde D.A.G. 1982. Körpelicherhaltene scyphozoen - reste aus dem Jungpräkambrium Brasiliens. Geologica et Paleontologica, 16:1-18.

Hardie L.A. \& Shinn E.A. 1986. Carbonate depositional environments. Part 3: Tidal flats. Colorado School of Mines Quartely, 81:59-74.

Hasui Y. \& Almeida F.F.M. 1970. Geocronologia do Centro-Oeste brasileiro. Bol. Soc. Bras. Geol., 19:1-26.

Halverson G. P., Maloof A.C., Hoffman P.F. 2004. The Marinoan glaciation (Neoproterozoic) in northeast Svalbard. Basin Research, 16:297-324

Hennies W.T. 1966. Geologia do Centro-Norte, Mato Grosso. Tese de Doutoramento, Instituto Politécnico, Universidade de São Paulo, S Paulo, $65 \mathrm{p}$.

Hidalgo R.L.L. 2002. Análise micropaleontológica das Formações Tamengo e Guaicurus, Grupo Corumbá (MS) e Formação Araras (MT), Transição do Neoproterozóico - Fanerozóico. Dissertação de Mestrado, Instituto de Geociências, Universidade de São Paulo, S. Paulo, 139 p.

Hoffman P.F. \& Schrag D.P. 2002. The Snowball Earth hyphothesis: test- ing the limits of global change. Terra Nova, 14:129-155.

Hoffman P.F., Kaufman A.J., Halverson G.P., Schrag D.P. 1998. A Neoproterozoic Snowball Earth. Science, 281:1342-1346.

James N.P., Narbonne G.M., Kyser T.K. 2001. Late Neoproterozoic cap carbonates: Mackenzie Mountains, northwestern Canada: precipitation and global glacial meltdown: Can. J. Earth Sci.,38:1229-1262.

Kahle C.F. 2002. Seismogenic deformation structures in microbialites and mudstones, Silurian Lockport Dolomite, northwestern Ohio, U.S.A. J. Sediment. Res., 72:201-216.

Kendall A.C. \& Harwood G.M. 1996. Marine evaporites: arid shorelines and basins. In: H.G. Reading (Ed.) Sedimentary Environments:Processes, Facies and Stratigraphy. Blackwell Science, pp.:281-324.

Kendall C.G.S.C. \& Warren J. 1987. A review of the origin and setting of tepees and their associated fabrics. Sedimentology, 34:1007-1028.

Kennedy M.J. 1996. Stratigraphy, sedimentology, and isotopic geochemistry of Australian Neoproterozoic postglacial cap dolostones: deglaciation, $\delta^{13} \mathrm{C}$ excursions, and carbonate precipitation. J. Sediment. Res., 66:1050-1064.

Kennedy M.J., Christie-Blick N., Sohl L.E. 2001. Are Proterozoic cap carbonates and isotopic excursions a record of gas hydrate destabilization following Earth's coldest intervals? Geology, 29:443-446.

Kerans C. \& Tinker S.W. 1997. Sequence Stratigraphy and characterization of carbonate reservoirs. SEPM, 130p. (Short course notes, 40).

Lisboa M.A.R. 1909. Oeste de São Paulo, sul do Mato Grosso: geologia, indústria mineral, clima, vegetação, solo agrícola, indústria pastoril. Rio de Janeiro, Tipografia do Jornal do Commercio, 172p.

Luz J.S., Oliveira A.M., Lemos D.B., Argolo J.L., Souza N.B., Abreu Filho W. 1978. Projeto Província Serrana. Relatório Final. Goiânia, DNPM/CPRM. v. 1., 136p.

Maciel P. 1959. Tilito Cambriano (?) no Estado de Mato Grosso. Bol. Soc. Bras. Geol., 8:31-9.

Nemec W. \& Steel R.J. 1984. Alluvial and coastal conglomerates: their significant features and some comments on gravelly masslow deposits. In: E.H. Koster \& R.J. Steel (Eds.) sedimentology of gravels and Conglomerates. Canadian Soc. Petrol. Geol., p.1-31 (Memoir 10).

Nogueira A.C.R. 2003. A plataforma carbonática Araras no sudoeste do Cráton Amazônico, Mato Grosso: estratigrafia, contexto paleoambiental e correlação com os eventos glaciais do Neoproterozóico. Tese de Doutoramento, Instituto de Geociências, Universidade de São Paulo, São Paulo, 173 p.

Nogueira A.C.R. \& Riccomini C. 2004. Depósitos siliciclásticos costeiros influenciados por maré e tempestades da Formação Raizama, Neoproterozóico da Faixa Paraguai, MT. In: SBG, Cong. Bras. Geol., Araxá, 42, Resumos extendidos, CD-Rom

Nogueira A.C.R., Riccomini C., Sial A.N. 2001a. Capa carbonática pósVaranger no Sw do Cráton Amazônico, MT: evidência de glaciação global (Snowball Earth). In: SBG, Simp. Geol. Amaz, 7, Belém, Resumos extendidos, $C D$-Rom.

Nogueira A.C.R., Riccomini C., Kerkis A., Fairchild T.R.; Hidalgo R.L. 2001b. Hydrocarbons in carbonate rocks of the neoproterozoic Alto Paraguaia Group, Mato Grosso, Brazil. In: An. Acad. Bras. Ciênc., S. Paulo, Resumo das Comunicações, v. 73, p. 464.

Nogueira A.C.R., Riccomini C., Sial A.N., Moura C.A.V., Fairchild T.R. 2003b. Soft- sediment deformation at the Neoproterozoic Puga cap carbonate (southwestern Amazon Craton, Brazil): conformation of rapid icehouse to greenhouse transition in snowball Earth. Geology, 31:613-616.

Obermeier S.F., Gohn G.S., Weems, R.E., Gelinas R.L., Rubin, M. 1985. Geologic evidence for reccurrent moderate to large earthquakes near Charleston, South Carolina. Science, 227:408-411.

Olivatti O. 1976. Contribuição à Geologia da Faixa Orogênica ParaguaiAraguaia. In: SBG, Cong. Bras. Geol., 29, Ouro Preto, Resumos, p. 12.

Oliveira A.I. de \& Leonardos O.H. 1943. Geologia do Brasil. 2ed. Rio de Janeiro, Serviço Informação Agrícola, Série Didática, n. 2, 813p.

Oliveira A.I. de \& Moura P. 1944. Geologia da região de Corumbá e minérios de manganês e ferro do Urucum, Mato Grosso. Rio de Janeiro, DNPM, Boletim da Divisão de Geologia e Mineralogia, n. 62, p.13-29.

Oliveira M.A.M. 1964. Reconhecimento geológico expedito na região do Alto Paraguai. São Paulo, PETROBRÁS, DEB5P, Relatório Técnico Interno, 266, 26p. 
Petri S., Coimbra A.M., Amaral G., Ojeda y Ojeda H., Fúlfaro V.J., Ponçano W.L. 1986. Código brasileiro de nomenclatura estratigráfica. Rev. Bras. Geoc., 16:370-415.

Pratt B.R., James N.P., Cowan C.A. 1992. Peritidal carbonates. In: R.G. Walker \& N.P. James (Eds.) Facies Models: response to sea level change. Geol. Assoc. Canada, p. 303-322.

Ribeiro Filho W. \& Figueiredo A.J.A. 1974. Reconhecimento geológico da região oeste de Mato Grosso. In: SBG, Cong. Bras. Geol., 28, Porto Alegre. Anais, p.27-35.

Ribeiro Filho W., Luz J.S., Abreu Filho W. 1975. Projeto Serra Azul. Goiânia, DNPM $\square / C P R M, 104 p$. (Relatório final).

Scorza E.P. 1960. Geologia de Diamantino, Estado do Mato Grosso, Brasil. Notas Preliminares e Estudos. Rio de Janeiro, Div. Geol. Miner, 113p.

Shinn E.A. 1983. Birdseyes, fenestrae, shrinkage pores, and loferites: a reevaluation. J. Sediment. Petrol., 53:619-628.

Silva Júnior J.B.C da., Nogueira A.C.R., Riccomini C., Sial A.N., Petri S., Trindade R.I.F.; Hidalgo R.L. 2005. Isótopos de carbonoe oxigênio de arenitos carbonáticos neoproterozóicos da região de Mirassol d'Oeste, SW do Cráton Amazônico. In: SBG, Cong. Bras. Geoq., 10., Resumos extendidos, CD-ROM.

Stow D.A.V. 1986. Deep clastic seas. In: H.G. Reading (Ed.) Sedimentary Environments: Processes, Facies and stratigraphy. Oxford, Blackwell Scientific Public. p. 399-444.

Sumner D.Y. \& Grotzinger J.P. 1996. Were kinectics of Archean calcium carbonate precipitation related to oxigen concentration. Geology, 24:119-122.

Trindade R.I.F., Font E., Dagrella-Filho M.S., Nogueira A.C.R., Ricco- mini C. 2003. Low-latitude and multiple geomagnetic reversals in the Puga cap carbonate: slow carbonate precipitation just after the snowball Earth. Terra Nova, 00:1-6.

Trompette R. 1994. Geology of Gondwana (2000-500 Ma). Pan-African-Brasiliano aggregation of South America and Africa. Rotterdam, Balkema, 350p.

Tucker M.E. 1992. Sedimentary Petrology. 2ed. Blackwell Scientific Publications, 260p.

Vieira A.J. 1965. Estratigrafia e estrutura da região de Rondonópolis, MT. Ponta Grossa, PETROBRÁS, 8p. (Relatório Técnico Interno).

Walde D.H.G., Leonardos O.H., Hahn G., Hahn R., Plufg H. 1982. The first Precambrian megafossil from South America, Corumbella werneri. An. Acad. Bras. Ciênc., 54:461.

Walker R.G. 1992. Facies, facies models and modern stratigrahic concepts. In: R.G. Walker \& N.P. James (Eds.) Facies Models - Response to Sea Level Change. Ontario, Geological Association of Canadá, p.1-14.

Zaine M.F. 1991. Análise dos fósseis de parte da Faixa Paraguai (MS, MT) e seu contexto temporal e paleoambiental. Tese de Doutoramento, Instituto de Geociências, Universidade de São Paulo, S. Paulo, $218 \mathrm{p}$.

Zanchi A. 1992. Tectonic and liquefaction structures in the Loreto Basin, Boja California (Mexico). Synsedimentary deformation along a fossil fault plane. Geodin. Acta, 5:187-202.

Manuscrito A1606 Aprovado em 18 de outubro de 2006 